2016 Modular and Offsite Construction (MOC) Summit

Edmonton, Alberta, Canada, September 29 - October 01, 2016

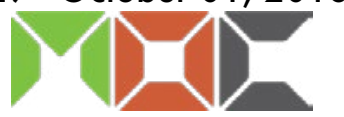

\title{
Lessons from Sweden: How Australia Can Learn from Swedish Industrialised Building
}

\author{
Duncan William MAXWELL ${ }^{1 *}$ and Mathew AITCHISON ${ }^{2}$ \\ ${ }^{1}$ PhD candidate, Faculty of Architecture, Design and Planning, University of Sydney \\ ${ }^{2}$ Associate Professor, Faculty of Architecture, Design and Planning, University of Sydney \\ *Corresponding author's e-mail: dmax6791@uni.sydney.edu.au
}

\begin{abstract}
Over the past decade, Australia has witnessed increased interest in industrialised building, particularly in the production of housing. This has happened under many different banners, including: prefabricated, modular, transportable and offsite construction methodologies. This interest has grown from a combination of factors, including: increased rate of housing construction and density; rising property and construction costs; the desire for increased efficiency and productivity; and a concern for the quality and sustainability of building systems. Historically, Australia has played an episodic role in the emergence of prefab and transportable buildings since the colonial era, but it does not have a longstanding industrialised building industry. In this context, an analysis of the experiences of North American, European and Japanese examples, provides valuable insights. This paper focuses on Sweden's approach to industrialised building and the lessons it holds for the emerging Australian sector.

Sweden represents a valuable case study because of similarities between the two countries, including: the high standard of living, cost of labour, and design and quality expectations; along with geographic and demographic similarities. Conversely, stark differences between the national situation also co-exist, notably climate, business approaches, political outlook, and cultural factors. In the 1950s, Swedish companies exported prefab houses to Australia to combat the Post-War housing shortage, which also supplies a historical dimension to the comparison. Most importantly, Sweden boasts a longstanding industrialised building industry, both in terms of practice and theory.

This paper will survey and compare the Swedish industry, and its potential relevance for Australia. Areas of discussion include: the relationship between industry and academy (practice and theory); the diversity of technique and methodologies and how they may be adapted; platform thinking (technical and operational); the staged industrialisation of conventional practices; and the importance of a socially, environmental and design-led practice of building.
\end{abstract}

\section{KEYWORDS}

Sweden; Australia; Industrialised House Building; International Case Study 


\section{INTRODUCTION}

Sweden's mature industrialised house building industry is one of the world's leading exponents of off-site construction. Market penetration is significant, $90 \%$ of single-family dwellings in Sweden are built using timber frame (Nord, 2008), and of this sector up to $70 \%$ are built off-site. Multiresidential construction is undergoing innovation in Sweden, and around $15 \%$ of apartments (Höök 2008) involve industrialised production methods. This strength in innovation and uptake presents a valuable case-study for researchers to consider and interpret the factors leading to Sweden's success. In this search for understanding, a research trip was undertaken by the authors to investigate the changing approaches and industrialisation of construction in Sweden.

Recent developments in Australia have led to a renewed appetite for construction innovation. Structural changes to the economy are underway as a decade-long resources boom comes to an end and the staged withdrawal of the remaining car manufacturers is emblematic of a broader manufacturing downturn. Construction remains one of the fundamental pillars of the domestic economy, highlighted by the Federal Government's efforts to stimulate the sector during the Global Financial Crisis by means of the 'Nation Building and Jobs plan' which financially supported construction employment. Eight years later, policy seeks to stimulate the sector through less direct financial means, instigating research and innovation projects that seek to develop and enhance the sector, while also creating an environment to assist the transition of manufacturing.

At first glance, Sweden and Australia would not seem to have an obvious shared history when it comes to prefabricated houses. Yet in 1950, Australia sent a trade delegation to Europe on a fact finding mission, in an attempt to address an urgent housing shortage. The aim, was to "investigate the large scale importation of prefabricated houses, and prospects of bringing out teams of workmen to erect them..." ("Housing Mission for Overseas" 1950). The mission found that Swedish builders produced the highest quality homes, and reported back that "Suitable houses can be provided in any quantity likely to be needed by Australia" ("Housing Mission finds ample Prefab Houses" 1950). It was proposed that around 40,000 houses could be imported from overseas each year to help meet the annual shortage of 100,000 homes. Yet from 1950-53, only 30,000 were brought to Australia from Sweden, Britain and France (“"Too Many' Prefabs Imported" 1953), as debate shifted from considering imported prefabs as a long-term option to government support for local industry.

Today, the economies of Sweden and Australia bear parallels in statistical terms, with near identical GDP per capita (World Bank / OECD 2014), and similar patterns of growth over the past 30 years. Furthermore, Sweden enjoyed a boost to GDP in the early 1980s through deregulation, while Australia experienced a similar boost from the mining boom of the early 2000s, leading the economies to where they are today. Labour costs are generally similar, especially in manufacturing (Bureau of Labor Statistics 2012), and construction costs are widely paralleled, evidenced by statistics (Statistics Sweden 2016), and anecdotal conversation during the research visit.

As well as such similarities, there are some clear economic structural differences, such as Sweden's widely known high tax revenue. While both countries enjoy high export rates, Sweden's are focused on 'value-added' manufactured goods, while Australia's have been driven by 'raw' commodities. 
The implications of Australia's changing economy are gradually being understood and it is in both similarities and differences that lessons are learned for how best to structure change. Sweden's construction industry presents a range of important lessons for Australian companies and researchers looking to engage with industrialised building methods. In observation, these lessons have been grouped into five core points: Industrial and Academic Collaboration, Construction Methods, Gradual Industrialisation, The Platform Approach and Contextual Issues.

\section{RESULTS AND DISCUSSION}

\section{Industrial and Academic Collaboration}

Universities have been integral to the development of industrialised construction through their work in collaboration with Swedish industry. The creation of the Development Fund of the Swedish Construction Industry (SBUF) has helped this relationship develop. The fund was established in 1983 to replace a government-managed research levy that had existed since the 1950s but had become unwieldy (Bröchner and Grandinson 1992), with the aim of encouraging research cooperation between companies and with academia. Today, the independent fund has around 3,000 members who contribute, it operates with a board and committee structure which processes applications for research projects, resulting in around 100 funded projects per year (SBUF 2011).

Following changes to building regulations in the mid-1990s to allow the use of timber in multistorey instances, a period of co-operation resulted in research which was focused on resolving technical construction and safety issues for how to construct these new, taller, buildings. The relationship between academia and industry was further enhanced by a national strategy for the use of timber in construction, initiated by the Swedish government in 2003. The release of the national strategy encouraged a greater emphasis on process considerations, through increased industrialisation of processes in the construction industry (Nord, 2008).

Swedish universities have continued this progression with many working on applied, or 'live' research projects. These projects can follow individual construction projects studying targeted aspects such as logistics or design modularity, to provide direct, quantifiable, statements of improvements. Alternatively, the projects take a holistic view of construction, and consider aspects such as the business model or overall construction process. Industry co-operates by providing places for PhD candidates to work in their offices on these collaborative projects with autonomy. After projects have reached completion, it is not uncommon to find these researchers employed in industry with the freedom to continue academic relationships. The familiarity of academic and industrial working processes, structures and constraints that these researchers possess allows for a dynamic and responsive working environment.

Construction research in Sweden is commonly instigated a number of ways. Across the study trip, the spectrum of research observed incorporated developers; builders; academia; and government, working both individually and collectively as required. Endeavours varied in scale, most being small scale innovations which were incremental in nature. At the other end of the spectrum, fullscale construction projects such as NCC Kompleet or the Pan-European ManuBuild project are also represented. 
Recognising the importance and value of these relationships has been of great value, resulting in projects that are organised to be beneficial to the range of stakeholders involved. This open spirit of collaboration not only provides one of the fundamental preconditions for success and innovation in industrialised construction, but for the continual improvement this approach demands.

\section{Construction Methods}

To the uninitiated, Sweden is timber, yet a diversity of construction methodologies are utilised within the industrialised construction sector, some of which are discussed further below.

Single-family housing producers, known domestically as 'Type House' manufacturers, use the elemental timber frame constructed on flat production lines as the dominant method, yet in multiresidential construction the range is diverse and no single system dominates.

Precast concrete emerged as the primary means for building apartments among large construction companies following Sweden's mid-20 ${ }^{\text {th }}$ century construction boom. Still the dominant construction system for multi-storey apartment buildings, concrete retains an embedded advantage following decades of favourable regulatory conditions, though this has not prevented recent innovation. One notable project discussed was the NCC Kompleet research project which ran for 6 years and developed a highly finished lightweight concrete modular system. The project was discontinued, but spin-off pre-cast concrete systems are used by NCC based on some of the key findings of this project.

Following the regulatory changes of the 1990s, timber has increased its market share of apartment building. A number of companies have subsequently developed industrialised timber building methods. These approaches are largely modular, either through stud frame on an engineered timber chassis, or a balloon frame system into which the module's floor is bolted. Investigations are also being conducted into the viability of using mass timber, with an 8-storey CLT apartment building constructed in Stockholm.

Hybrid methodologies are also in existence, a notable example of which combines a post-tensioned lightweight precast concrete flooring system with a light gauge steel framed curtain wall. An elemental system, this approach combined a range of parts from the company's various specialised factories around Sweden, cherry-picking industrialised elements from within their pre-existing traditional construction expertise to create a fully industrialised offering for the market.

This selective approach to industrialised construction was also observed with another contractor who had recently moved into the Swedish market, using sub-contracted manufactured elements from a range of fabricators, to create a flexible industrialised offering with a modular service pod at each apartment's core. This contract management approach would be familiar to Australian construction companies, and perhaps represents a quick, agile and low start-up cost approach to creating an industrialised offering in a new market.

The range of construction methods demonstrated by companies in Sweden shows that successful industrialised construction is often path dependent, being as much the result of refining existing expertise, as the discovery of new and innovative construction systems and materials. 


\section{Gradual Industrialisation}

Industrialised construction did not happen quickly. Some 'Type' house manufacturers started out as timber mills looking to add value to their sawn timber products and, aided by the Swedish Government's publishing of standardised house drawings in the 1920s (Lessing 2015), took the next step of combining the milled timber in to simple house frames.

Common to the history of prefabrication around the world, Sweden's industrialised construction journey has been intermittent, and often tied to housing shortages where quick and efficient construction was required. This was demonstrated during the 1960s, when the Swedish government introduced the Miljonprogrammet, which aimed to build a million residences over a decade. Headway was made and industrialised techniques investigated, but by the 1970s this progress abruptly stopped due to oversupply. The previously mentioned changes to timber building regulations during the mid-90s prompted another phase of innovation, which has had longevity and been sustained until today, expanded to industrialised construction research beyond timber.

Most industrialised house builders in Sweden have been refining their unique approaches for over a decade, in some cases more than twenty years. Most had a background in traditional construction before moving operations either partially or fully off-site, while some have origins as timber merchants looking to vertically integrate their supply chain.

The gradual industrialisation has occurred through the development of construction methodologies, but also through the development of processes for factory environments, consideration of the customer, and giving detailed consideration to the market sector of operation.

The drivers for industrialisation have been nominated variously as the pursuit for a higher quality product, a more efficient construction process, the development of a low-cost housing model, or looking to expand a company's range of offerings simply so that an off-site construction approach was available to customers. Understanding and nominating this aim early on in the transition has enabled Swedish industry to retain a clear focus on the primary aim for the industrialisation of construction, ultimately resulting in strong Swedish off-site identity.

\section{The Platform Approach}

This Swedish off-site identity has been nurtured by research which has followed a similar journey of gradual refinement as witnessed in industry. Research units, such as that led by Lars Stehn at Luleå University, with a background in timber engineering, were initially tasked with the resolution of technical and material questions in order to advance the transition to industrialised construction. In considering these technical questions, thoughts began to turn to process considerations at a time when the Japanese manufacturing philosophy of 'Lean' was at its zenith. Jerker Lessing at Lund University established a clear definition of industrialised construction for the Swedish context (Lessing, 2006), which subsequently has been built upon through work with industry by researchers such as Helena Johnsson and Gustav Jansson to refine unique, context specific platforms for industrialised construction.

Platforms for industrialised construction exist in all contexts, though it is the open study, description, and refinement of the platform approach has come to differentiate Swedish off-site 
construction. This work to understand platforms has aided the explanation and understanding of the integrated processes that are required for off-site construction, yet often difficult to achieve.

Industry platforms are diverse, demonstrated by those which offer low-cost housing and feature tightly constrained designs with limited opportunity for client yet manage to deliver high quality built outcomes with little need for unique documentation. This controlled approach is common to the single family dwelling market around the world, where houses are chosen from catalogues and tailored discreetly to the customer's preference. Increasingly, Swedish builders are shifting their platforms towards the other end of the spectrum, where more flexible processes allow for greater customisation by designer and client. This development allows greater customer input and relies on increased design flexibility, this form of platform also opens a broader market sector and range of sites increasing the value of a company's offering.

This search for flexibility through customisation, has been one of the driving forces behind the development of the platform approach, in response to criticisms of lean manufacturing. Lean has been able to respond to low-level customisation during the assembly phase of production, but for construction a much earlier customer input is common and required (Stump and Badurdeen 2009). Platforms seeks to manage design inputs by creating working systems known as 'views' for use during the design-phase, by the client and designer, and subsequently during manufacture and installation (Malmgren et al. 2010). The platform approach also provides a holistic definition of a businesses' operation by describing their components, knowledge, processes and people/relationships. These definitions, once stated, then allow for clarity of roles and channels of feedback to develop and be monitored, in an atmosphere of continual improvement.

These business and market-specific platforms underscore that there is no singular 'best practice' approach to off-site construction, and that instead there is a complexity in constraints and parameters at play. This complexity exists at a number of levels, not just in the physical endproduct, but also in the working processes, knowledge, and relationships.

\section{Contextual Issues}

The platform approach begins to explain and define the range of issues that are at play in a company's immediate system of construction and market of its operation. However, there are a broader range of issues that exist at a societal level which have an impact on the definition of a company's platform as well as the success and uptake of industrialised construction more broadly.

These contextual issues vary in scale, from the local municipality to the impact of the European Union. The most immediate impact is at that of the local municipality of operation or where projects will be developed. In Sweden, land is often owned by local government who will place conditions on proposed designs in order to approve its release. As is the case in many countries, development planning compliance can be time intensive, so it be can advantageous to adopt a product approach a demonstrated strategic advantage of some industrialised house builders, who will use their design platform to negotiate with local authorities in advance of such development applications. The European Union has also had an impact on the development of industrialised construction. In mandating a EU-wide target for zero-energy buildings by 2020, the Swedish government has responded by gradually tightening environmental regulations and building performance requirements. These factors have forced companies' platforms to be flexible and 
responsive to regulatory change, highlighting the importance of incorporating feedback from a range of sources to contribute and drive their continual improvement.

Sweden has a history of social democratic governments, and this has carried through into housing policy and design expectations. Dating back to the Miljonprogrammet's underlying aim of 'good housing for all' (Hedman 2008), still this attitude pervades anecdotally, mentioned in conversation and evidenced often by the output of house manufacturers who produce high quality products suited to a wide market, yet not necessarily 'tailored' to the end-user. As mentioned, company's platforms are increasingly being used to respond to specific markets, in order to produce more suitable housing. This ability to provide opportunities for customisation has unlocked new, lucrative markets that historically only traditional construction has been able to touch.

\section{CONCLUSION}

Visiting Swedish industrialised house builders has established the basis of an important case study to the ongoing research which supports the emerging Australian industrialised construction. Initiating the process of understanding and developing these lessons is important if momentum towards industrialised construction is to be sustained in less mature environments. Translation of knowledge across geographic contexts aids development of new practices, but also assists the original subject of the study, enabling feedback from this interpretation and implementation to better understand the status of their own industry, and where future paths of innovation may lie.

The collaborative spirit of research and development that exists between industry and academia, has driven progress in Sweden over the past two decades. While not necessarily unique to Sweden, there are few countries which have achieved this degree of integration, and we believe this has been one of the foundations for the success of the industrialised house building industry.

Accepting that there is not a single way of working, is another important lesson to be learned. The Swedish case-study shows that the construction approach that is successful for one company, may not be for another. This lesson contributes to the fact that construction is complex, and industrialised construction is as much about the method being used to build as the processes which support the method and which explain how the overall business model is integrated with the market of operation. This way of working describes a 'solutions-mode' of problem solving, as much as it is about the product approach that companies in Sweden promote.

The story of industrialised construction in Sweden reveals that lasting change occurs gradually, often over decades. Initial developments in Australia may be rapid, as industrialised construction methods and practices are adopted, yet after this initial growth phase, it is important to keep in mind the lessons of staged industrialisation that Swedish companies exhibit beyond the early years.

The development of the platform concept helps to demonstrate the importance of integrated, context-specific, working methods which rely on feedback to provide a basis for continual improvement. The development and definition of this approach in Sweden has shown the value of understanding and critiquing existing ideologies, for example the Japanese approach to Lean, and working to refine and test for use in a new context to create a more appropriate philosophy, not just for the context but for the manufactured construction industry more broadly. 
Conducting this geographical study has highlighted the importance of understanding the broad contextual issues that are at play, as well as the specific factors of success. In an increasingly connected world, these types of studies will increase in relevance, so it is important to develop methods and strategies for understanding the lessons, while at the same time provide a matrix through which findings can be interrogated and applied to new settings. The Swedish approach to industrialised construction describes a way of working, a culture, a mentality. This is the core finding of this research, that it is this intangible lesson that we must learn, which is also the hardest lesson, as it is not a set of rules but an attitude. Far from disqualifying these lessons, this is all the more reason to understand them more fully - which we hope this paper has gone some way.

\section{Acknowledgements}

We would like to acknowledge Scott Hedges who introduced us to Sweden's off-site construction industry, and who alerted us to the Swedish prefabs imported to Australia during the early-1950s. Thanks are also due to new friends and colleagues in Sweden, without whose generosity of time, access and ideas this paper would not be possible.

\section{References}

Bröchner, J., and Grandinson, B. (1992). “R\&D Cooperation by Swedish Contractors.” Journal of Construction Engineering and Management, 118(1), 3-16.

Bureau of Labor Statistics. (2012). "International Labor Comparison [Sweden]." Bureau of Labor Statistics, <http://www.bls.gov/fls/country/sweden.htm> (Jul. 4, 2016).

Hedman, E. (2008). "A history of the Swedish system of non-profit municipal housing." BoverketSwedish Board of Housing.

Höök, M. (2008). "Lean culture in industrialized housing: a study of timber volume element prefabrication.” (L. Stehn, ed.).

Lessing, J. (2006). "Industrialised house-building: concept and processes." Department of Construction Sciences, Lund University, Lund.

Lessing, J. (2015). "Industrialised House-Building.” (A. Ekholm and L. Stehn, eds.), Lund, Sweden.

Malmgren, L., Jensen, P., and Olofsson, T. (2010). "Product modelling of configurable building systems-a case study.” Journal of Information Technology in Construction, 15, 354-368.

Nord, T. (2008). Prefabrication strategies in the timber housing industry - Case studies from Swedish and Austrian markets. Luleå University of Technology, Luleå, Sweden, 1-110.

SBUF. (2011). SBUF: Complete Report. SBUF, 1-3.

Statistics Sweden. (2016). Statistics Sweden: Prices for Newly Produced Dwellings. Statistics Sweden.

Stump, B., and Badurdeen, F. (2009). "Integrating lean and other strategies for mass customization manufacturing: a case study." Journal of Intelligent Manufacturing, 23(1), 109-124.

World Bank / OECD. (2014). "GDP per Capita." The World Bank, $<$ http://data.worldbank.org/indicator/NY.GDP.PCAP.CD?contextual=default\&end $=2014 \&$ locations $=$ AU-SE\&start $=1983 \&$ view $=$ chart $>($ Jul. 4, 2016).

"Housing Mission finds ample Pre-fab Houses." (1950). The Canberra Times, Canberra, p.5.

"Housing Mission for Overseas." (1950). The Advertiser, Adelaide, p.1.

“"Too Many' Prefabs Imported.” (1953). The Advertiser, Adelaide, SA, p.4. 